\title{
Marcel Martel, Canada the Good: A Short History of Vice Since 1500 (Waterloo: Wilfrid Laurier University Press, 2014). 196 pp. \$29.99 Paperback.
}

In the introduction to his carefully researched and expansive book, Canada the Good: A Short History of Vice Since 1500, Marcel Martel provides this definition for "vice" from the Oxford English dictionary: "depravity or corruption of morals; evil, immoral, or wicked habits or conduct; indulgence in degrading pleasures or practices." Working with this as the basis, he underscores two characteristics of vice as defined through Canadian history: first, these behaviours have been considered dangerous because they are thought to corrupt individuals by their immorality, and secondly, vices are held to be reprehensible because those who indulge in them obtain pleasure from these unhealthy and disrespectful practices. The individual corruption experienced by individuals, the overlapping nature of vices where one bad habit like smoking gives rise to other intersecting vices like taking alcohol or drugs, and the pleasure experienced by the range of vices has made them difficult to eliminate. To even control vices, he argues, requires a broad societal consensus on the dangers presented by them, often resulting in moral panics of one kind or another. While one might quibble with the definition Martel offers for vice, it works well as a base-line for his discussion of a wide range of feared activities. It might be noted, in addition, that in instances where vices have resulted in moral movements, fears have escalated beyond individual's activities to the group's. Particularly when these groups were poor, with alien cultures that were misunderstood, vices could easily transmute into terrifying spectres for the host community. While Martel describes just such processes, he tends to under-rate the group phenomenon in considering some pastimes as benign and others as vices.

Within this construct, Martel discusses some of the main vices about which some groups fretted from first contacts to the present: alcohol, gambling, tobacco use, drugs, sexual orientation and expression, prostitution, birth control and abortion. Each "vice" is examined in four periods, 1500 to 1700 with earliest contacts between Europeans and First Nations peoples, in the colonial era of 1700 to 1850, during the heyday of moral panics and the evangelical Protestant ascendancy of 1850 to 1920 and finally, 1920 to the present. The chronological divisions work well (better than the three periods identified by Strange and Loo in their Making Good: Law and Moral Regulation in Canada, 1867 - 1939) and encourage comparisons of how definitions of vices developed and receded along with the creation of moral bureaucracies to control them through culture, religion, professions like medicine or social work, or the state through legal frameworks and policing. Martel observes that while some of these vices continue to be acknowledged as pernicious and potentially dangerous (for example, smoking), others have dropped off the map almost entirely, now considered not 
vices but relatively benign social processes actively supported by governments, like gambling.

The analysis applied by Martel to each vice is consistent with the literature: some cultural practices by a subjugated ethnic or racialised group (as, for example, sexuality among First Nations groups) can easily be redefined by an imperial power as a vice (as, for example, by the Roman Catholic Church or Protestant denominations' missionaries). Other practices, like drinking, have clear health implications for consumers. Martel argues that in most cases, the moral criticism of these practices has waned in favour of health concerns since the 1920s. In fact, Martel's final chapter he calls, "No Longer Vices - Call Them Health Issues." While this is often the case, it is a stretch to argue that issues such as abortion or prostitution or the taking of street drugs or even the legalisation of gay marriage does not remain a moral issue for many Canadians, while at the same time acknowledging some behaviours as addictions. Many Canadians are comfortable with habits of this kind being grounded in several motivations at once.

Drawing on much of the period and scholarship underpinning Strange and Loo's Making Good, Martel updates the historiography, drawing on an impressive range of scholarly and popular works in English and French. One of the book's outstanding contributions is to include literature from French Canada as an organic component, rather than the usual "tack-on" approach. In particular, the seemingly inconsistent position of the Roman Catholic Church in defending French Canadians' morality in every period as contrasted with the simpler role of Protestant denominations, especially in the late nineteenth century, is very convincingly argued. This factor alone makes the book both unusual and useful. Further, Martel's tracing of modern vices' status by Canadian legislatures and courts until late 2013 offers a timely reminder of the ongoing public debate around "vices" that still create anxiety and fear in the community.

Because of its accessibility as a text, its shortness (at $158 \mathrm{pp}$. before notes), its subject matter and its timeliness, this volume is well positioned to serve as a course textbook at either the undergraduate or graduate level. For the undergraduate student, this book offers not only a catalogue of how the term "vice" has been an instrument of oppression, but also a careful and sensitive analysis of how moral issues have been taken up by broad social movements and made their own. For instance, Martel's interpretation of why the abortion issue became - and remains - so central to second-wave feminism in Canada and beyond would help students understand the enduring importance of these issues on the Canadian landscape as they continue to inform political, economic and social policy, women's history and health institutions. It is a welcome addition to the literature in this field.

Sharon Anne Cook University of Ottawa 